\title{
DIREITOS INDIVIDUAIS
}

Lucas Ferreira Furlan

Universidade do Oeste Paulista - UNOESTE. E-mail: lucasfurlan94@hotmail.com

\section{RESUMO}

Este artigo discorre acerca do importante tema dos direitos individuais. Analisam-se quais os tipos de direitos individuais, quem são seus destinatários, e quais são as suas verdadeiras finalidades. Será realizado um estudo detalhado dos princípios constitucionais que circundam o tema e sua devida aplicação na atual sociedade. $\mathrm{O}$ artigo possui diversas citações de profissionais renomados em suas áreas como: Alexandre de Moraes, Luiz Alberto David Araujo, Vidal Serrano Nunes Júnior, Garcia de Enterria entre outros, que vão auxiliar o leitor na dissipação de duvidas referente aos assuntos abordados. $\mathrm{O}$ artigo se encerra com uma ampla conclusão que aborda cada tema citado no referente texto.

Palavras-chave: Direitos, princípios, constituição, lei e destinatários.

\section{1- INTRODUÇÃO}

Direitos individuais que podem ser tidos como um ramo dos direitos fundamentais que se encontram previstos principalmente no art. $5^{\circ}$ da nossa atual Carta Magna e em outras partes do texto constitucional podem ser definidos como limitações impostas pelo povo aos seus mandatários, para proteger direitos indispensáveis à pessoa humana.

Após as grandes revoluções burguesas do final do século XVIII, o indivíduo passou a ser considerado como uma pessoa detentora de direitos, e não mais como mero súdito. Com isto, o Estado passa a ser submisso a uma constituição e a defesa do indivíduo, perante os seus governantes, passa a ser-lhe assegurada, extinguindo-se, assim, o sistema absolutista que imperava em grande parte do mundo, na época.

\section{2- DESTINATÁRIOS}

Os direitos individuais podem ser explícitos ou implícitos.

Os considerados explícitos são aqueles previstos expressamente no texto da Constituição Federal. Como exemplo, os contidos no art. $5^{\circ}$ da CF. e seus incisos, em especial os previstos no caput do mencionado artigo, a saber: "Inviolabilidade do direito à vida, à liberdade, à igualdade, à segurança e à propriedade." (CF, 1988, art. $5^{\circ}$ caput.). É justo, também, que se dê destaque aos princípios tributários da legalidade e da anualidade, que são direitos individuais explícitos previstos no art.150 da Lex Legum. 
Além disso, a Constituição admite a existência de direitos individuais implícitos, ou seja, cujo reconhecimento decorre de interpretação do texto da Lei das Leis. Isto se evidencia pela leitura do art. 5ㅇ, parágrafo 2 , que reconhece a existência de outros direitos individuais "decorrentes do regime e dos princípios por ela adotados, ou dos tratados internacionais de que a República Federativa do Brasil seja parte".

Os destinatários das normas dos direitos individuais, que são os direitos fundamentais, são os brasileiros e os estrangeiros residentes no Brasil. Grande parte de nossa doutrina entende que esses direitos devem estender-se a toda e qualquer pessoa, mesmo àquelas que se encontre apenas em trânsito, pelo solo nacional.

Está explícito na lição do constitucionalista Alexandre de Moraes (2012, p.33):

Observe-se, porém, que a expressão residentes no Brasil deve ser interpretada no sentido de que a Carta Federal assegura ao estrangeiro todos os direitos e garantias mesmo que não possua domicílio no País, só podendo, porém assegurar a validade e gozo dos direitos fundamentais dentro do território brasileiro, não excluindo, pois, o estrangeiro em trânsito pelo território nacional, que possui igualmente acesso às ações, como o mandado de segurança e demais remédios constitucionais.

Assim, podemos concluir com a seguinte perspectiva:

Os estrangeiros residentes no País têm garantidos outros direitos além dos previstos no art. 5ㅇ da atual Constituição, pelo próprio princípio da igualdade abordado nesse dispositivo constitucional, desde que não incompatíveis com a situação de estrangeiro.

Além disso, os estrangeiros não residentes no país têm alguns direitos fundamentais assegurados pela Constituição brasileira. Embora um estrangeiro, mesmo que de passagem ou clandestino no país, tenha direito à impetração de um mandado de segurança ou de um habeas corpus, há precedentes do Supremo Tribunal Federal nesse sentido.

\section{3- DIREITOS E PRINCÍPIOS QUE SE DESTACAM NA ANÁLISE DOS DIREITO INDIVIDUAIS.}

O primeiro e mais elementar dos direitos humanos, pré-requisito para a existência e exercício de todos os demais direitos, é o direito à vida. Nem o Estado, nem qualquer membro da sociedade tem o direito de ceifar a vida de um semelhante, de decidir quem vai viver e quem vai morrer, salvo nos casos de guerra, declarada onde a pena capital pode vir a ser aplicada.

Entretanto o direito à vida vai além de simplesmente viver, mas, sim, viver com dignidade, podendo o indivíduo ter acesso a serviços de saúde, educação, segurança e cultura de qualidade. Uma maneira muito comum de se desrespeitar o direito à vida, no mundo moderno, é a de 
impedir que membros da sociedade tenham uma vida digna. Não faltam exemplos, acima de tudo, em nosso país, de pessoas morrendo em filas de hospitais, por falta de atendimento; e de adultos que sequer foram alfabetizados. É humilhante que, na sexta maior economia do mundo, apenas 7,9\% da população consiga concluir uma graduação (Censo. 2010). Vale, novamente, citar uma lição do constitucionalista Alexandre de Moraes (2012. p. 34): “a Constituição Federal proclama, portanto, o direito à vida, cabendo ao Estado assegurá-lo em sua dupla acepção, sendo a primeira relacionada ao direito de continuar vivo e a segunda de se ter uma vida digna quanto à subsistência".

Portanto, não podemos deixar-nos absorver pela ideia de que o direito à vida se limite apenas a viver, devemos ser incansáveis na cobrança ao Estado, para que este garanta, cada vez mais uma vida digna ao seu povo.

Um grande debate que envolve o direito à vida no Brasil nos últimos anos, é o da legalização do aborto. Visto isto, é valido destacarmos os ensinamentos do biólogo Botella Lluziá (apud Moraes, 2012, p. 35):

O embrião ou feto representa um ser individualizado, com uma carga genética própria, que não se confunde nem com a do pai, nem com a da mãe, sendo inexato afirmar que a vida do embrião ou do feto está englobada pela vida da mãe.

Dessa forma, entendemos que, enquanto vigorar a presente Constituição Federal, isso será impossível, já que a mesma garante, em uma clausula pétrea, a inviolabilidade do direito à vida desde o seu início, que, do ponto de vista biológico, ocorre com a fecundação do óvulo pelo espermatozoide. Assim sendo, tem a vida viável início com a nidação, quando de fato se inicia a gravidez.

Em relação ao direito fundamental à igualdade ou isonomia, esse princípio deve produzir efeitos sobre todas as pessoas do país. O legislador e o aplicador da lei devem tratar, igualitariamente, todos os indivíduos, sem distinção de qualquer natureza.

A igualdade não é absoluta, mas apenas formal, onde os desiguais são tratados desigualmente e o Estado se apresenta, perante os entes privados, com relativa supremacia legal.

Ensina-nos o constitucionalista Alexandre de Moraes (2012, p.35):

A Constituição Federal de 1988 adotou o princípio da igualdade de direitos, prevendo a igualdade de aptidão, uma igualdade de possibilidades virtuais, ou seja, todos os cidadãos têm o direito de tratamento idêntico pela lei, em consonância com os critérios albergados pelo ordenamento jurídico. Dessa forma, o que se veda são as diferenciações arbitrárias, as 
descriminações absurdas, pois, o tratamento desigual dos casos desiguais, na medida que se desigualam, é exigência tradicional do próprio conceito de Justiça.

Infelizmente, nem sempre conseguimos ver, com clareza a aplicação desse princípio em nosso país. Desse modo para termos mais nitidez em nosso raciocínio, basta-nos analisar que, enquanto um cidadão tem que trabalhar seis dias por semana, em uma jornada de oito horas diárias, para ganhar pouco mais de um salário mínimo, o expediente, no Congresso Nacional, vai apenas de terça a quinta-feira, com os parlamentares ganhando um salário infinitamente maior, além de outras diversas regalias, como passagens aéreas, auxílio moradia etc.

A propósito, a lição de Araujo e Serrano Nunes (2013, p.177):

O princípio da igualdade, assim, não pode ser reduzido a um comando destinado ao aplicador da lei. Antes, tem por direcionamento o estado e a sociedade. Tem em mira o Estado representado por suas várias funções e órgãos (Executivo, Legislativo, Judiciário e Ministério Público, etc.) e os indivíduos que, nas relações privadas, não podem adotar condutas incompatíveis com o princípio examinado.

Em toda sociedade, a igualdade deve ser objeto de reflexão de debate e de investigação. Seu foco volta-se, sempre, para o alcance de uma maior isonomia de todos perante a lei, porém não deve reduzir-se apenas a isso mas também a uma constante busca da redução das desigualdades dentro da própria sociedade.

No art. $5^{\circ}$, II, da Constituição da República, encontramos o Princípio da Legalidade, que determina que ninguém será obrigado a fazer ou deixar de fazer coisa que a lei não determine. Este princípio visa a combater possíveis arbitrariedades que o Estado possa tentar cometer, fazendo com que as obrigações dos cidadãos só possam ser criadas por meio de espécies normativas elaboradas de acordo com o que determina o processo legislativo constitucional.

Complementando o raciocínio, ressalta Garcia de Enterria (apud Moraes, 2012, p. 41):

Quanto ao conteúdo das leis, a que o princípio da legalidade remete, fica também claro que não é tampouco válido qualquer conteúdo (dura lex, sed lex), não é qualquer comando ou preceito normativo que se legitima, mas somente aqueles que se produzem "dentro da Constituição" e especialmente de acordo com sua "ordem de valores" que, com toda explicitude, expressem e, principalmente, que não atentem, mas que pelo contrario sirvam as direitos fundamentais. 
De todos os princípios e direitos aqui estudados, o da legalidade é, sem dúvida, aquele que mais protege o cidadão contra uma possível volta do absolutismo ou de alguma tentativa do Estado de violar a lei com alguma arbitrariedade.

Por fim, encontramos o princípio da reserva legal, que pode ser tido como uma decorrência do princípio da legalidade. Dessa forma, não será condenável afirmar-se que o princípio da legalidade possui uma abrangência mais ampla do que o da reserva legal, sendo este um aprofundamento daquele.

Sucintamente podemos explicar a reserva legal, também chamada de reserva de lei, com o fato de que determinadas matérias só podem ser tratadas mediante a lei, sendo vedado o uso de qualquer outra espécie normativa, pois a própria constituição é que estabelece quais matérias serão essas.

\section{4- CONCLUSÕES.}

Tema essencial e de grande relevância em um mundo onde se intensifica, a cada dia, o trânsito entre pessoas de diferentes nacionalidades e culturas, nos mais diversos países, é indispensável à compreensão de que os direitos individuais e coletivos constitucionais são assegurados a todos os que estiverem presentes no Território Nacional, portanto aos brasileiros ou não.

O direito à vida, a despeito de todas as alegações de insuficiência material do Estado brasileiro, inclui não somente o direito de nascer, e mesmo este está abalado, visto que recentes estudos da ONU mostram que o número de abortos clandestinos, no Brasil, pode ultrapassar um milhão de fetos por ano, sem que se note grande interesse do Estado em estancar essa verdadeira matança de seres humanos. Além disso, o direito de viver deve ocorrer de forma digna, cabendo ao Estado garantir acesso de qualidade aos bens e serviços que venham a prestar, caminhando-se para um "Estado de Bem Estar Social".

O direito à igualdade, para ser assegurado, deve contar com a superação de diferentes bloqueios de toda sorte pelos indivíduos na sociedade brasileira. Deve esse ser assegurado a todos os membros da sociedade independente de cor da pele, crença ou posição social. Infelizmente, ainda nos dias atuais, em pleno século XXI, falar-se que grupos de pessoas das classes mais favorecidas se portam ou agem como iguais aos demais cidadãos das classes menos abastadas é uma ingenuidade. Dizer-se que certos parlamentares e ou governantes se sentem em igualdade 
com os demais cidadãos brasileiros também não chega nem perto de representar a atual realidade.

Mas, sem dúvida, o mais marcante de tudo o que foi dito é que os mandatários que tomam posse e juram observar cumprir e defender o que determina o Magno Texto Republicano o façam com fidelidade. Que os governantes passem a adequar a Constituição à verdadeira realidade do país, e não simplesmente ao seu plano eleitoreiro. Só quando isso começar a acontecer, de fato, é que veremos os direitos individuais serem efetivamente aplicados.

\section{REFERÊNCIAS}

ARAUJO, SERRANO NUNES. Os Direitos Individuais e Coletivos. In: ARAUJO, SERRANO NUNES. Curso de Direito Constitucional. São Paulo: Verbatim, 2013. p. 175-249.

BASTOS, Celso Ribeiro. Curso de direito constitucional. São Paulo: Celso Bastos Editor, 2002.

Morais, A. Direitos e Garantias Individuais. In: Morais, A. Direito Constitucional. São Paulo: Atlas, 2012. p. 30-41.

MAFRA, Francisco. Direitos individuais e coletivos: Destinatários da proteção. Direito à vida, princípio da igualdade, princípio da legalidade e reserva legal. In: Âmbito Jurídico, Rio Grande, VIII, n. 20, fev 2005. Disponível em:

<http://www.ambitojuridico.com.br/site/index.php?n_link=revista_artigos_leitura\&artigo_id=797 >. Acesso em: 08 ago 2013.

Souza, D. F. DIREITOS INDIVIDUAIS. Disponível em: http://teoriadaconstituicaodf.blogspot.com.br/2009/07/direitos-individuais.html. Acesso em: 07 ago. 2013. 